\title{
Avaliação do Jogo Educativo Mundo de Euclides: Uma abordagem Multi-Perspectiva
}

\author{
Sebastião Rogério da Silva Neto ${ }^{13}$, Eraylson Galdino da Silva ${ }^{12}$, Aline Ferreira \\ Barbosa $^{12}$, Wilk Oliveira dos Santos ${ }^{13}$, Anderson Alves de Souza ${ }^{12}$, Millena Lauyse \\ Silva de Oliveira ${ }^{12}$, Andson Marreiros Balieiro ${ }^{12}$
}

${ }^{1}$ Universidade de Pernambuco (UPE)

Caixa Postal 55.294-902 - Garanhuns - RS - Brasil

${ }^{2}$ Centro de Informática - Universidade Federal de Pernambuco (UFPE)

Caixa Postal 50740-560 - Recife - PE - Brasil

${ }^{3}$ Instituto de Computação - Universidade Federal de alagoas (UFAL)

Caixa Postal 57072-900 - Maceió - AL - Brasil

\{anderson.dercio, millena.lauyse\}@gmail.com, \{afb3, egs, amb4\}cin.ufpe.br, \{srsn, wos\} @ic.ufal.br

\begin{abstract}
Resumo. Jogos educativos são vistos como uma valiosa ferramenta a ser utilizada no processo de ensino e aprendizagem de Matemática, como em axiomas Euclidianos, por exemplo. Entretanto, antes da aplicação no ambiente escolar, tais jogos necessitam ser avaliados sob diversas perspectivas a fim de garantir a sua efetividade pedagógica. Neste aspecto, este trabalho apresenta a avaliação do jogo educativo Mundo de Euclides nas perspectivas de motivação, experiência do usuário, conhecimento e aprendizado. Os resultados obtidos mostram que, embora o Mundo de Euclides seja efetivo nas perspectivas, melhorias no jogo precisam ser realizadas. A abordagem de avaliação adotada neste artigo é extensivel a outros jogos sem grandes alterações.
\end{abstract}

\begin{abstract}
Educational games are seen as a valuable tool to be used in the teaching and learning of Mathematics (e.g. Euclidean axioms). However, before their application in the school environment, such games need to be evaluated from different perspectives in order to ensure their teaching effectiveness. In this respect, this work presents the evaluation of the educational game 'Mundo de Euclides' in terms of motivation, user experience, knowledge and learning. Results show that although the game is effective in the evaluated aspects, improvements need to be made in the game to address some gaps. The approach adopted in this paper is extensible to other games without major changes.
\end{abstract}

\section{Introdução}

A sociedade contemporânea é caracterizada pelo uso cada vez mais frequente das tecnologias digitais da informação e comunicação (TDIC) na organização das mais diferentes práticas sociais como atividades físicas, relacionamentos, atividades profissionais e educacionais, por exemplo (Ribeiro, 2012). Dentre estas diversas atividades, percebe-se que o investimento em tecnologias e a sua inserção no âmbito 


\section{CBIE-LACLO 2015}

Anais dos Workshops do IV Congresso Brasileiro de Informática na Educação (CBIE 2015)

educacional são cada vez maiores. Atualmente, é comum encontrarmos escolas equipadas com laboratórios de informática e estudantes em sala de aula com dispositivos como notebooks, tablets, principalmente nos grandes centros urbanos.

De acordo com Silva Neto et al. (2013), a integração de TDIC no ambiente escolar possibilita discussões quanto aos métodos e práticas sobre o uso destas ferramentas para auxiliar o processo de ensino e aprendizagem, onde deve-se buscar alternativas para, através do uso destas tecnologias, obter maneiras de facilitar o processos de ensino e aprendizagem.

Entre os métodos com esta finalidade, encontra-se a utilização de jogos tradicionais ${ }^{1}$ e/ou jogos digitais. Estes, quando utilizados nas atividades de ensino, podem propiciar momentos lúdicos e interativos no processo de aprendizagem [Sá, Teixeira e Fernandes ,2007]. Nesta perspectiva, os jogos digitais são apontados por autores como Buchinger et al. (2012) e Reinoso et al. (2012) como uma alternativa para atrair $\mathrm{o}$ interesse $\mathrm{e}$ atenção dos estudantes, tornando a aprendizagem lúdica e interessante.

Atualmente, pesquisas demonstram uma série de benefícios em incluir os jogos digitais no processo ensino e aprendizagem. Eles são um rico instrumento para a construção do conhecimento, transformando o ato de jogar em ato de aprender e ensinar e construindo os objetivos necessários para se alcançar uma aprendizagem significativa, como elucidado por Medeiros et al. (2013). Além disso, Silveira (1998) afirma que os jogos são criados para divertir os alunos e com isto prender sua atenção e assim auxiliar no ensino e aprendizagem, estimulando a autoaprendizagem por descoberta.

$\mathrm{Na}$ Matemática verifica-se que os conceitos estão atrelados ao desenvolvimento do raciocínio lógico, o qual estimula a criatividade e a capacidade de resolver problemas. No entanto, segundo Fiorentini e Lorenzato, (2006) os alunos sentem dificuldade em resolver problemas matemáticos devido a abstração que envolve os conteúdos da disciplina. Este é um problema constante no processo de ensino e aprendizagem. Adicionalmente, os autores apontam que os alunos aprendem a resolver/interpretar melhor os problemas matemáticos através de materiais manipulativos, desenhos, esquemas ou jogos, por exemplo.

A literatura apresenta vários jogos para auxiliar o ensino de Matemática Silva [Junior et al. 2006]. No entanto, percebe-se a ausência de jogos que abordem conceitos como ponto e retas (paralelas e concorrentes). Tais conceitos são essenciais para a construção de outros mais complexos na Geometria, onde a não compreensão destes conceitos-base pode ocasionar maior dificuldade na assimilação dos mais complexos.

Além disso, como mostrado em Silva et al (2014), pesquisas realizadas com professores demonstram a necessidade de criação e uso de jogos educativos voltados para o ensino destes conceitos. Neste aspecto, em Silva et al. (2014) é apresentado um jogo educativo intitulado Mundo de Euclides. Ele visa auxiliar o processo de ensino aprendizagem de conceitos básicos relacionados a Geometria Euclidiana. Os autores descrevem o processo de desenvolvimento e em Souza et al.(2014) são apresentados os resultados da aplicação do jogo.

É importante, porém, que os jogos educativos, enquanto desenvolvidos, possam ser avaliados durante sua aplicação sob diferentes aspectos simultaneamente como computacionais, de interface e pedagógicos, uma vez que eles influenciam o tempo e a forma como a aprendizagem é alcançada. Entretanto, esta avaliação é por vezes inexistente, como aponta Savi et al. (2010). A maioria dos trabalhos sobre jogos digitais

\footnotetext{
${ }^{1}$ Alguns autores usam outros termos para definir o que chamamos de jogos tradicionais, como, jogos físicos, jogos concretos, jogos não digitais ou jogos de console.
} 


\section{CBIE-LACLO 2015}

Anais dos Workshops do IV Congresso Brasileiro de Informática na Educação (CBIE 2015)

voltados para educação destaca especificamente ou o processo de desenvolvimento do jogo, ou a avaliação do jogo em aspectos isolados como interface, computacionais ou pedagógicos, abstendo-se de tratá-los simultaneamente.

Neste sentido, este artigo apresenta a avaliação do jogo educativo Mundo de Euclides em termos de diferentes perspectivas como motivação, experiência do usuário, conhecimento e aprendizagem com o intuito analisar se o jogo em questão contribui de forma positiva para a compreensão de conceitos de Geometria. Diante dos aspectos delineados, este artigo encontra-se assim organizado. A Seção II apresenta os trabalhos relacionados. A Seção III faz uma breve descrição do jogo avaliado. A proposta de avaliação é descrita na Seção IV. A Seção V apresenta a metodologia adotada neste trabalho. Resultados são analisados na Seção VI. Considerações finais e trabalhos futuros são apresentados na Seção VII.

\section{Trabalhos Relacionados}

Nesta seção, apresentam-se trabalhos que abordam a utilização de jogos digitais no ensino de conceitos geométricos. Busca-se não apenas retratar o que o jogo aborda em termos de conceitos relacionado à Geometria, mas também resultados de avaliações referentes à aprendizagem e a usabilidade dele, com o intuito de clarificar as diferenças e contribuições do trabalho proposto com os da literatura.

Nascimento (2012) apresenta o software Geogebra, desenvolvido e proposto para auxiliar o ensino de conceitos de Geometria. No software é possível realizar construções de pontos, vetores, segmentos, retas, entre outros. $\mathrm{O}$ autor destaca como vantagem que o software proporciona diversas representações de um mesmo objeto interagindo entre si. Entretanto, o trabalho não apresenta resultados que demonstrem a efetividade do seu uso no aprendizado dos alunos, bem como o nível de complexidade da sua utilização.

O mesmo se verifica em Machado et al. (2008), que apresenta um jogo 3D chamado GeoEspaçoPEC. Seu conteúdo aborda conceitos da geometria espacial como identificação de figuras planas, conceito de área da base, cálculo de área total e elementos e aresta, por exemplo. Seu objetivo é possibilitar aos alunos do $5^{a}$ e $6^{a}$ ano do ensino fundamental a revisão dos assuntos aplicados em sala. Entretanto, nota-se a ausência de dados que apresentem a experiência do usuário e qual contribuição em relação a aquisição de conhecimento para esse aluno ao utilizar o jogo.

Observa-se que os jogos apresentados possuem o mesmo objetivo, ensinar de forma lúdica conceitos de geometria aos alunos. Entretanto, para verificar a efetividade deles no processo de ensino e aprendizagem faz-se necessário avaliá-los sob diferentes perspectivas como motivação do usuário ao utilizar o jogo, qual a experiência que o usuário tem durante o jogo, conhecimento e aprendizagem obtida, os quais são explorados através de diferentes pontos. Avaliar sob apenas uma destas perspectivas pode não refletir a efetividade do software no alcance do seu objetivo, uma vez que ele pode ter uma excelente interface gráfica e inicio interessante, satisfazendo alguns aspectos da motivação, mas não oferecer os desafios nos níveis apropriados durante o jogo ou proporcionar ao usuário a lembrança das informações apresentadas no jogo, que são aspectos da experiência do usuário e conhecimento, respectivamente.

Neste sentido, este trabalho apresenta a avaliação do jogo educacional, "Mundo de Euclides", sob diferentes perspectivas, a saber: motivação, experiência do usuário e conhecimento e aprendizado a fim de obter uma avaliação geral do jogo e sugerir possíveis melhorias em alguma perspectiva ou aspectos específicos. 


\section{CBIE-LACLO 2015}

Anais dos Workshops do IV Congresso Brasileiro de Informática na Educação (CBIE 2015)

\section{O Jogo Mundo de Euclides}

O enredo do jogo trata-se da necessidade de Juninho, personagem principal, de estudar para a prova de Geometria. Juninho vai para escola e durante a aula de matemática a professora avisa que haverá prova de Geometria. Ao chegar em casa, ele vai para o quarto estudar e acaba por adormecer. Em um sono profundo, ele sonha que está em um mundo chamado "Mundo de Euclides". Neste mundo, Juninho vê o vilão (chamado de Senhor Quadrado) e seus aliados capturando Euclides, o pai da Geometria. O objetivo de Juninho é justamente concluir todas as fases do jogo para salvar e libertar Euclides. O Mundo de Euclides foi criado com base nos axiomas Euclidianos (pontos e retas). O jogo apresenta como principal característica a ludicidade. Ele é constituído por cinco diferentes fases, onde as quatro primeiras fases estão associadas aos axiomas euclidianos e a última apenas para diversão do usuário.

\section{Proposta}

Este artigo apresenta uma proposta e aplicação de avaliação do jogo educativo Mundo de Euclides sob várias perspectivas. Para isso, o jogo foi avaliado tanto sob as perspectivas adotadas pelo modelo de avaliação proposto por Savi et al. (2010), quanto na perspectiva de aprendizagem dos conceitos subjacentes. O modelo de Savi et al. (2010) é baseado no modelo de avaliação de Kirkpatrick (1994), nas estratégias de motivação do modelo ARCS de Keller (2009) e nos objetivos educacionais da Taxonomia de Boom (1956). Ele avalia o jogo quanto às perspectivas de Motivação, Experiência do Usuário e Conhecimento. Assim, ele busca avaliar se um jogo: (i) consegue motivar os estudantes a utilizarem o recurso como material de aprendizagem; (ii) proporciona uma boa experiência nos usuários; e (iii) se gera uma percepção de utilidade educacional entre seus usuários (ou seja, se os alunos acreditam que estão aprendendo com o jogo).

No elemento motivação, a finalidade foi observar se o Mundo de Euclides é interessante e motiva o aluno a aprender sobre a Geometria. Em relação à experiência do usuário, foi avaliado o nível de satisfação dos jogadores em utilizarem o Mundo de Euclides. $\mathrm{O}$ aspecto do conhecimento busca evidenciar se os alunos recordam as informações apresentadas durante o jogo.

Como, na perspectiva de Conhecimento, o modelo proposto por Savi et al. (2010) é focado apenas na memória do usuário sobre que ele lembra após jogar, um bom resultado nesta perspectiva não reflete necessariamente uma aprendizagem significativa, ou seja, que o aluno será capaz de aplicar os conceitos apresentados em outros ambientes, ou situações, como em testes tradicionais em sala de aula, por exemplo.

Para suprir esta lacuna do modelo e avaliar o jogo sob a perspectiva de aprendizagem, adotou-se um teste de Matemática. Este teste possuía questões referentes aos conteúdos abordados no jogo. Assim, o propósito deste teste é verificar se o uso do Mundo de Euclides proporciona algum aprendizado significativo para os usuários sobre os conteúdos específicos de Matemática presentes nele, bem como verificar se o jogo está cumprindo o seu papel principal, ser uma ferramenta de apoio ao aprendizado de axiomas da Geometria.

Para a realização da avalição proposta, foi necessário adaptar o questionário do modelo proposto por Savi et al. (2010). As modificações consistiram em tornar o questionário menos exaustivo, diminuindo a quantidade de questões, e eliminando possíveis redundâncias ou questões com objetivos muito próximos. Além de alterações na forma de escrita das questões, fazendo-se o uso de uma linguagem mais clara e objetiva para a faixa etária dos alunos adotados na avaliação. 


\section{CBIE-LACLO 2015}

Anais dos Workshops do IV Congresso Brasileiro de Informática na Educação (CBIE 2015)

O modelo de Savi et al. (2010) tem sido adotado em avaliações de jogos educativos em variadas áreas. Em Aumiller et al. (2011), os autores relatam o uso do modelo com objetivo de avaliar o jogo educativo intitulado Negociação Trabalhista sob dois aspectos: usabilidade e aprendizado. Oliveira (2013) utilizou o questionário proposto por Savi para avaliar um jogo educativo voltado para o ensino e aprendizagem de teste de software. Através do mesmo questionário, com adaptações para o públicoalvo, Siqueira et al. (2011) descreve a validação de um jogo educativo com finalidade de ajudar crianças com dificuldades de leitura e escrita.

Nosso trabalho difere dos anteriores, pois não se limita a avaliar o jogo educacional utilizando apenas o modelo de Savi et al. (2010), mas também insere a perspectiva de aprendizagem na avaliação, a qual não é contemplada no modelo. Assim, é possível avaliar o nível de contribuição que o jogo Mundo de Euclides traz para reforçar o aprendizado dos alunos nos axiomas de Geometria.

\section{Metodologia}

Para realizar a avaliação do jogo Mundo de Euclides, uma turma do $7^{\circ}$ ano do Ensino Fundamental de uma escola pública da cidade Garanhuns-PE foi adotada. O jogo foi testado e avaliado pelos próprios alunos.

A metodologia utilizada neste trabalho tem uma natureza qualitativa e quantitativa. Para avaliar a aprendizagem dos alunos e a qualidade do jogo sob as perspectivas de motivação, experiência do usuário e conhecimento, dois questionários foram adotados. Um contendo questões matemáticas elaboradas junto com o professor de Matemática da turma alvo e outro baseado no modelo de avaliação proposto por Savi et al. (2010) utilizando as questões definidas nele.

O teste de Matemática era formado por 4 questões, onde cada uma estava relacionada ao conceito abordado em cada fase do jogo, considerando somente as 4 primeiras fases. Assim, a primeira questão era sobre a correta representação de ponto. A segunda sobre o conceito de reta. A terceira sobre retas paralelas e a última sobre retas concorrentes.

A avaliação do jogo foi dividida em quatro atividades principais, com a seguinte sequência: ATV1: Aplicação do teste matemático aos alunos; ATV2: Utilização do jogo pelos alunos; ATV3: Aplicação do teste matemático novamente; ATV4: Aplicação o teste de qualidade do jogo aos alunos.

Como planejado, o teste matemático foi aplicado duas vezes aos alunos participantes do experimento, antes (pré-teste) e depois (pós-teste) da utilização do jogo educacional. Isto buscou verificar o impacto da utilização do jogo no conhecimento dos alunos sobre os conceitos de geometria presentes no jogo e, consequentemente, na resolução das questões.

A fim de definir o desenho (plano) de experimento mais adequado a ser aplicado nesta pesquisa, o fluxo contendo as quatro etapas descritas anteriormente foi realizado duas vezes: uma no experimento piloto e outra no experimento final.

O experimento piloto contou com participação de 10 alunos. Neste experimento, buscou-se verificar a adequabilidade dos aspectos adotados na pesquisa, como linguagem adotada nos questionários, tempo estimado para a realização das atividades, por exemplo, e verificar quais eram passíveis de melhorias. Tais melhorias foram contempladas no experimento final, que contou com a participação de 20 alunos. Embora os alunos pertençam a mesma turma, os alunos participantes de um teste não participaram do outro. Isso ocorreu para verificar se de fato o jogo era capaz de reforçar os conhecimentos dos alunos no assunto abordado na disciplina de Matemática. Como os 10 alunos iniciais já haviam utilizado o jogo no experimento piloto, isso poderia 
influenciar na resolução do teste de matemática aplicado antes da utilização do jogo no experimento final.

De acordo com os resultados obtidos e observações realizadas na aplicação do experimento piloto, modificações nos dois questionários foram realizadas. No questionário de Matemática (teste) observou-se que os alunos não compreenderam o enunciado de algumas perguntas, o que interferiu diretamente nos resultados obtidos. Com isso, as questões do teste foram reformuladas, adotando uma linguagem mais apropriada para série escolar dos alunos.

Quanto ao segundo questionário duas modificações foram realizadas: redução do número de questões e escrita por extenso dos pontos da escala Likert adotados nelas. Ao todo, 38 perguntas haviam sido adotadas no experimento piloto. Já no experimento final, este número foi reduzido para 30. A redução do número de questões se deu por dois motivos. Primeiro, o questionário estava muito extenso de ser aplicado aos alunos, os quais apresentavam fadiga na sua resolução. Segundo, através de análise das questões, notaram-se questões com objetivos muito próximos que poderiam ser suprimidas sem prejuízo para a avaliação do jogo educativo. A modificação quanto escrita da escala no questionário ocorreu devido à falta de compreensão dos alunos em relação a siglas adotadas.

Além disso, o experimento final diferiu do piloto no seguinte aspecto. Enquanto no piloto, o teste de Matemática e o questionário de qualidade foram aplicados na mesma sala e no mesmo dia (ATV1-4). No experimento final, os alunos responderam o teste de Matemática no primeiro dia (ATV1) e em sala de aula. No segundo dia, eles utilizaram o jogo educacional (ATV2) e em seguida responderam o teste de Matemática e o segundo questionário no laboratório de computação (ATV3-4). Como o teste de Matemática (ATV1) era para o aluno responder de acordo com os seus conhecimentos prévios, optou-se por aplicá-lo na sala de aula. O segundo teste foi no laboratório porque os alunos deveriam jogar e em seguida responder novamente o teste de matemática e o questionário de qualidade (ATV2-4). Essa mudança na aplicação foi observada que os alunos demonstravam cansaço ao realizar os testes em apenas um dia e ansiedade para utilizar o jogo (ATV2) quando chegavam ao laboratório de computação, fazendo a ATV1 sem nenhuma atenção. A Tabela 1 sumariza algumas informações sobre o plano dos experimentos piloto e final.

Tabela 1 Especificações dos experimentos

\begin{tabular}{|c|c|c|c|c|c|}
\hline Experimento & $\begin{array}{c}\mathbf{N}^{\mathbf{0}} \text { de } \\
\text { Alunos }\end{array}$ & $\begin{array}{c}\mathbf{N}^{\mathbf{0}} \text { de questões } \\
\text { matemáticas }\end{array}$ & $\begin{array}{c}\mathbf{N}^{\mathbf{0}} \text { de questões } \\
\text { (questionário) }\end{array}$ & Tempo no Jogo & $\begin{array}{c}\mathbf{N}^{\mathbf{0}} \\
\text { dias }\end{array}$ \\
\hline Piloto & 10 & 4 & 38 & 25 & 1 \\
\hline Final & 20 & 4 & 30 & 25 & 2 \\
\hline
\end{tabular}

\section{Análise de Resultados}

Como experimento piloto objetiva clarificar quais as possíveis melhorias que poderiam ser realizadas no experimento final tanto em termos dedos questionários, quanto no fluxo de execuções das atividades, optamos por suprimir seus resultados neste trabalho. Inicialmente, os resultados sob a perspectiva de aprendizagem, obtidos no teste de Matemática, são analisados. Em seguida, aqueles relativos às perspectivas de motivação, experiência do usuário e conhecimento são apresentados.

\section{a) Análise quanto à aprendizagem}




\section{CBIE-LACLO 2015}

Anais dos Workshops do IV Congresso Brasileiro de Informática na Educação (CBIE 2015)

No experimento final, a avaliação dos resultados obtidos na aplicação do teste de matemática antes da utilização do jogo (ATV1), denotado como pré-teste, e os obtidos depois da utilização do jogo (ATV3), denotado como pós-teste, foi realizado da seguinte maneira. As três primeiras questões eram de múltipla escolha com apenas uma resposta correta. Assim, as respostas foram contabilizadas como corretas ou incorretas e obtido a porcentagem de acertos obtidos em cada questão. Já a última questão apresentava 4 sentenças em que o aluno deveria julgar cada uma como falsa ou verdadeira. Desta forma, para cada aluno, foi calculada a porcentagem de acertos nesta questão e, em seguida, considerando todos os alunos que realizaram o teste, obteve-se a porcentagem média de acertos ou erros. A Figura 1 apresenta os resultados obtidos em cada questão em termos de porcentagem de acertos.

Como se observa na Figura 1, para a questão 1, que tratava do conceito de pontos, a porcentagem de acertos obtida no pós-teste superou aquela obtida no pré-teste em 35\%. Esse resultado mostra que a primeira fase do jogo contribuiu para uma melhora significativa na aprendizagem dos alunos, reforçando seus conhecimentos prévios. Na questão 2, a melhoria obtida no pós-teste foi ainda maior. Obteve-se $45 \%$ a mais de acertos em relação ao pré-teste e alcançou-se, no total, 95\% de acertos. Isso mostra que a forma lúdica como o conceito de reta é apresentado na segunda fase do jogo traz grande benefícios para aprendizagem.

Diferente das duas questões anteriores, a questão 3, que abordava o conceito de retas paralelas, a porcentagem de acertos foi maior no pré-teste do que no pós-teste (ver Fig. 1), representado uma diferença de $10 \%$. Com este resultado, nota-se que a fase 3 do jogo não contribuiu da maneira esperada na melhoria dos resultados e consequentemente na aprendizagem dos alunos. Desta forma, uma revisão na forma como o conceito é abordado nesta fase, bem como em outros aspectos que serão avaliados em seguida, pode ser realizada a fim de ela alcance o propósito de auxiliar o aluno na compreensão do conceito de retas paralelas.

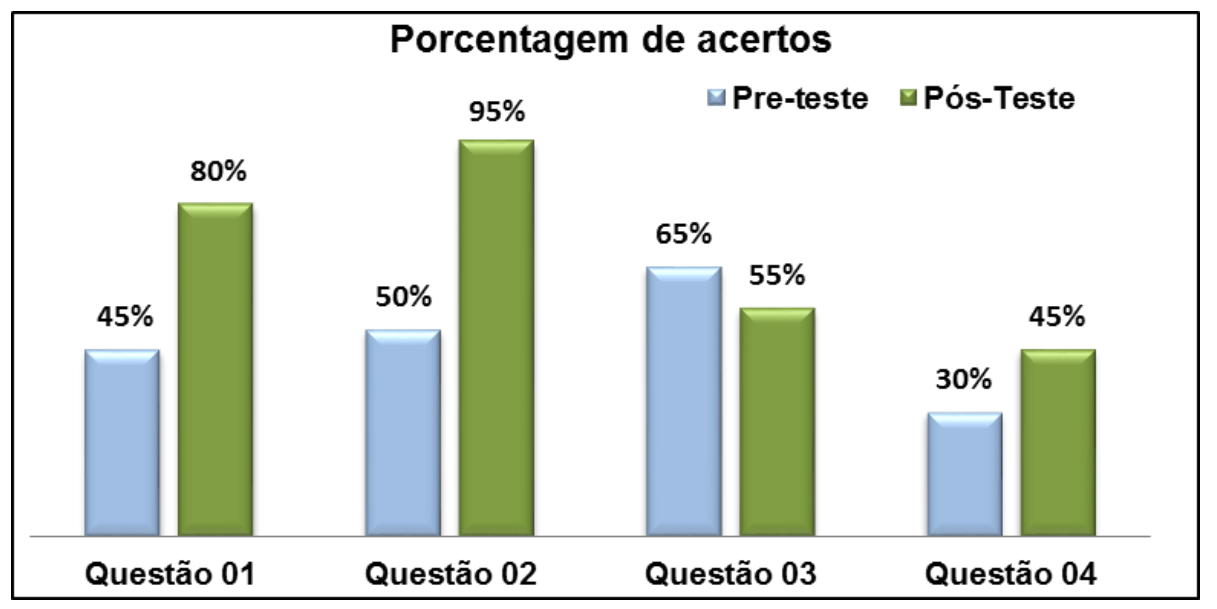

Figura 1. Porcentagem de acertos no teste de Matemática

A questão 4 por sua vez teve um aumento na porcentagem de acertos no pósteste comparado ao pré-teste (ver Figura 1). Esse aumento foi de $15 \%$ e mostra que a quarta fase do jogo contribuiu para uma melhor compreensão do conceito de retas concorrentes.

Quanto à aprendizagem, nota-se que, em geral, o jogo proporcionou uma melhor compreensão dos conceitos de Geometria envolvidos e que a sua utilização em sala de aula pode ser um forte aliado para reforçar os conceitos básicos de Geometria. Além disso, nota-se que melhorias devem ser realizadas na terceira fase do jogo a fim de 
corrigir possíveis falhas pedagógicas em sua execução. Além disso, um aspecto importante notado nestes resultados, é que o aluno, em geral, conseguiu compreender os conceitos apresentados no jogo e aplicá-los em tarefas que ele comumente realiza em sala de aula, ou seja, extraiu tais conceitos de um ambiente e os utilizou em outro.

\section{b) Análise quanto à motivação, experiência do usuário e conhecimento}

Para análise do jogo nas perspectivas de motivação, experiência do usuário e conhecimento, assertivas que contemplassem alguns aspectos importantes dentro de cada perspectiva foram utilizadas. Na perspectiva de motivação, os seguintes aspectos foram avaliados: atenção, relevância, confiança e satisfação. Desafio, habilidade e divertimento foram os aspectos avaliados na perspectiva de experiência do usuário. Para sistematizar a resposta dos alunos, foi adotada a escala Likert com 4 pontos, os quais são: concordo fortemente(CF), concordo(C), indiferente(I), discordo(D) e discordo fortemente(DF). Assim, o aluno selecionou um desses pontos como resposta de cada questão.

Tabela 2. Resultados na perspectiva de motivação

\begin{tabular}{|c|c|c|c|c|c|}
\hline Assertiva & $\mathbf{C F}$ & $\mathbf{C}$ & I & D & DF \\
\hline \multicolumn{6}{|l|}{ Atenção } \\
\hline Houve algo interessante no início do jogo que chamou minha atenção. & $10 \%$ & $75 \%$ & $10 \%$ & $5 \%$ & $0 \%$ \\
\hline \multicolumn{6}{|l|}{ Relevância } \\
\hline $\begin{array}{l}\text { Ficou claro para mim como o conteúdo do jogo está relacionado com coisas } \\
\text { que eu já sabia. }\end{array}$ & $30 \%$ & $60 \%$ & $0 \%$ & $5 \%$ & $5 \%$ \\
\hline O conteúdo do jogo é interessante. & $50 \%$ & $20 \%$ & $15 \%$ & $5 \%$ & $10 \%$ \\
\hline Eu poderia relacionar o conteúdo do jogo com coisas que já vi, fiz ou pensei. & $25 \%$ & $35 \%$ & $30 \%$ & $10 \%$ & $0 \%$ \\
\hline \multicolumn{6}{|l|}{ Confiança } \\
\hline O jogo foi mais difícil de entender do que eu gostaria. & $15 \%$ & $40 \%$ & $25 \%$ & $10 \%$ & $10 \%$ \\
\hline $\begin{array}{l}\text { O jogo tinha tanta informação que foi difícil identificar e lembrar dos pontos } \\
\text { importantes. }\end{array}$ & $30 \%$ & $15 \%$ & $20 \%$ & $25 \%$ & $10 \%$ \\
\hline O conteúdo do jogo é tão confuso que foi difícil manter a atenção nele. & $20 \%$ & $5 \%$ & $30 \%$ & $30 \%$ & $15 \%$ \\
\hline As atividades do jogo foram muitos difíceis. & $0 \%$ & $60 \%$ & $25 \%$ & $10 \%$ & $5 \%$ \\
\hline Eu não consegui entender uma boa parte do conteúdo do jogo. & $0 \%$ & $25 \%$ & $30 \%$ & $20 \%$ & $25 \%$ \\
\hline \multicolumn{6}{|l|}{ Satisfação } \\
\hline Senti-me realizado ao completar as fases do jogo. & $40 \%$ & $30 \%$ & $25 \%$ & $5 \%$ & $0 \%$ \\
\hline $\begin{array}{l}\text { As mensagens dos finais das fases me ajudaram a sentir recompensado pelo } \\
\text { meu esforço. }\end{array}$ & $25 \%$ & $40 \%$ & $25 \%$ & $5 \%$ & $5 \%$ \\
\hline Senti-me mais no ambiente do jogo do que no mundo real. & $15 \%$ & $40 \%$ & $15 \%$ & $25 \%$ & $5 \%$ \\
\hline Tive que me esforçar para ter bons resultados no jogo. & $20 \%$ & $50 \%$ & $5 \%$ & $15 \%$ & $10 \%$ \\
\hline Houve momentos em que eu queria desistir do jogo. & $60 \%$ & $25 \%$ & $10 \%$ & $0 \%$ & $5 \%$ \\
\hline
\end{tabular}

A Tabela 2 apresenta os resultados percentuais obtidos na perspectiva de motivação. Nota-se que a maioria dos estudantes concordou que houve algo interessante no jogo, bem como que ele apresenta uma boa relevância. Além disso, a maioria notou um relacionamento do foi apresentado no jogo com seus conhecimentos prévios, e a indicou a habilidade deles em aplicar tais conhecimentos trabalhados no jogo em outros cenários. Quanto ao aspecto de confiança, nota-se que 55\% dos alunos achou o jogo mais difícil do que gostaria. Entretanto, isso não significou que eles não entenderam o que foi abordado no jogo ou que não tiveram satisfação em jogá-lo. Uma revisão nos níveis de dificuldades das fases, através da adoção de uma transição mais suave, pode proporcionar melhor confiança aos alunos durante o jogo. Uma forma de se obter isso é através de inserção de novas fases no jogo. Entretanto, isso deve ser feito cuidadosamente para não afetar o aspecto de desafio, ou seja, adotar fases muito similares em termos de níveis de dificuldades pode desestimular o aluno durante o jogo. 
Os resultados em termos da perspectiva de experiência do usuário são apresentados na Tabela 3. Nota-se que a maior parte dos alunos sentiu-se estimulada a aprender com o jogo, continuar jogando e indicam que ele possui um equilíbrio em termos das fases. Em termos de competência, a maioria percebeu que obteve progresso na aplicação do jogo. E quanto ao divertimento, apesar de uma parcela dos alunos indicar que alguns pontos no jogo causaram irritação, a maioria indicou que gostou de jogar e que o jogaria novamente.

Tabela 3. Resultados na perspectiva de experiência do usuário

\begin{tabular}{|c|c|c|c|c|c|}
\hline Assertiva & $\mathbf{C F}$ & $\mathbf{C}$ & I & D & DF \\
\hline \multicolumn{6}{|l|}{ Desafio } \\
\hline Senti-me estimulado a aprender com o jogo. & $20 \%$ & $55 \%$ & $10 \%$ & $5 \%$ & $10 \%$ \\
\hline Eu gostei do jogo e não me senti ansioso ou entediado. & $25 \%$ & $25 \%$ & $20 \%$ & $15 \%$ & $15 \%$ \\
\hline O jogo me manteve motivado a continuar utilizando-o. & $20 \%$ & $55 \%$ & $15 \%$ & $10 \%$ & $0 \%$ \\
\hline Minhas habilidades melhoram a cada fase com a superação dos desafios. & $35 \%$ & $45 \%$ & $10 \%$ & $5 \%$ & $5 \%$ \\
\hline $\begin{array}{l}\text { Este jogo é equilibrado para mim, os desafios não são muito fáceis nem muito } \\
\text { difíceis. }\end{array}$ & $10 \%$ & $40 \%$ & $20 \%$ & $25 \%$ & $0 \%$ \\
\hline \multicolumn{6}{|l|}{ Habilidade/Competência } \\
\hline Eu alcancei rapidamente os objetivos do jogo. & $20 \%$ & $20 \%$ & $35 \%$ & $25 \%$ & $0 \%$ \\
\hline Senti que estava tendo progresso durante o desenrolar do jogo. & $20 \%$ & $50 \%$ & $15 \%$ & $15 \%$ & $0 \%$ \\
\hline \multicolumn{6}{|l|}{ Divertimento } \\
\hline Eu gosto de utilizar este jogo por bastante tempo. & $20 \%$ & $50 \%$ & $15 \%$ & $15 \%$ & $0 \%$ \\
\hline Quando interrompido, fiquei desapontado que o jogo tinha acabado. & $40 \%$ & $30 \%$ & $5 \%$ & $15 \%$ & $10 \%$ \\
\hline Eu jogaria este jogo novamente. & $30 \%$ & $35 \%$ & $10 \%$ & $5 \%$ & $10 \%$ \\
\hline Algumas coisas do jogo me irritaram. & $35 \%$ & $30 \%$ & $10 \%$ & $15 \%$ & $10 \%$ \\
\hline Fiquei torcendo para o jogo acabar logo. & $20 \%$ & $15 \%$ & $10 \%$ & $20 \%$ & $35 \%$ \\
\hline Achei o jogo meio parado. & $10 \%$ & $10 \%$ & $15 \%$ & $25 \%$ & $40 \%$ \\
\hline
\end{tabular}

Na perspectiva de conhecimento, os resultados obtidos foram satisfatórios (ver Tabela 4). Nota-se a relevância do jogo no auxilio a compreensão dos conceitos apresentados e sua aplicação em outros cenários. Além disso, a maioria dos alunos indicou que, mesmo após a finalização do jogo, consegue se lembrar de informações relacionadas aos conceitos apresentados.

Tabela 4. Resultados na perspectiva de conhecimento

\begin{tabular}{|c|c|c|c|c|c|}
\hline Assertiva & CF & $\mathbf{C}$ & $\mathbf{I}$ & D & DF \\
\hline $\begin{array}{l}\text { Depois do jogo consigo lembrar de mais informações relacionadas ao tema } \\
\text { apresentado no jogo. }\end{array}$ & $20 \%$ & $45 \%$ & $25 \%$ & $5 \%$ & $5 \%$ \\
\hline Depois do jogo consigo compreender melhor os temas apresentados no jogo. & $20 \%$ & $35 \%$ & $40 \%$ & $0 \%$ & $0 \%$ \\
\hline $\begin{array}{l}\text { Depois do jogo sinto que consigo aplicar melhor os temas relacionados com o } \\
\text { jogo. }\end{array}$ & $30 \%$ & $30 \%$ & $20 \%$ & $15 \%$ & $5 \%$ \\
\hline
\end{tabular}

\section{Considerações Finais}

Jogos educativos são vistos como uma valiosa ferramenta a ser utilizada no processo de ensino e aprendizagem de conceitos matemáticos, principalmente naqueles conteúdos que apresentam um nível maior de abstração, como por exemplos os axiomas Euclidiano. Entretanto, antes de sua aplicação no ambiente escolar, tais jogos necessitam ser avaliados sob diversas perspectivas a fim de garantir a sua efetividade pedagógica. Neste aspecto, este trabalho apresentou a avaliação do jogo educativo Mundo de Euclides nas perspectivas de motivação, experiência do usuário, conhecimento e aprendizado. 


\section{CBIE-LACLO 2015}

Anais dos Workshops do IV Congresso Brasileiro de Informática na Educação (CBIE 2015)

Os resultados obtidos mostraram que o Mundo de Euclides alcançou bons resultados nas perspectivas avaliadas e que ele auxilia na compreensão dos conceitos matemáticos envolvidos. Entretanto, algumas melhorias podem ser realizadas no jogo para que ele supere as lacunas identificadas, seja no aspecto pedagógico, seja em aspectos como número de fase, níveis de dificuldades, por exemplo.

\section{Referências}

Aumiller, A. L. G. et al. (2011) Uma Análise da Utilização de Jogos para Apoio ao Aprendizado em Negociação. In Simpósio Brasileiro de Jogos e Entretenimento Digital (SBGames).

De Oliveira, B. C. (2013) Testeg-Um Software Educacional para o Ensino de Teste de Software. Universidade Federal de Lavras.

Machado, et al. (2011). Uma Proposta de Jogo Educacional 3D com Questões Didáticas. In: Anais do Simpósio Brasileiro de Informática na Educação. (SBIECBIE). P. 621.

Mesquita, Leonardo et al. (2013) Education for Energy Efficiency Through an Educational Game. In: Frontiers In Education Conference, IEEE. IEEE, 2013. P. 535540.

Machado, L. S.; Morais, A. M. et. al.(2008) RPG para Ensino de Geometria Espacial e o Jogo GeoEspaçoPEC. In: VIII Ermac - Encontro Regional de Matemática Aplicada e Computacional. Natal - RN

Sarmanho, E. S. et al. (2011) Um Jogo Com Reconhecedor de Voz para o Ensino de Crianças com Dificuldade de Aprendizagem em Leitura e Escrita. Published By Semish.

Savi R., Wangenheim et al. (2010). Proposta de um Modelo de Avaliação de Jogos Educacionais. Novas Tecnologias na Educação (RENOTE), Porto Alegre, V. 8, N. 3

Savi R., Wangenheim C. G. V., Ulbricht, V., Vanzin, T., (2010). Proposta de um Modelo de Avaliação de Jogos Educacionais. Novas Tecnologias na Educação (RENOTE), Porto Alegre, V. 8, N. 3

Silva, Lidiane Figueiras et al.(2013) Ensinando Geometria a Deficientes Visuais: O Ambiente Dinâmico Geometrix. Revista Brasileira de Informática na Educação, V. 21, N. 02, P. 62.

Silva, Eraylson G. et al. (2014) O processo de desenvolvimento do jogo Mundo de Euclides para ensino da Geometria Euclidiana. In Simpósio Brasileiro de Jogos e Entretenimento Digital (SBGames).

Silveira, S. R. (1998). Estudo e Construção de uma Ferramenta de Autoria Multimídia para a Elaboração de Jogos Educativos. Instituto de Informática, Universidade Federal do Rio Grande do Sul.

Siqueira, E. S. et al. (2011) Um Jogo com Reconhecedor de Voz para o Ensino de Crianças com Dificuldade de Aprendizagem em Leitura e Escrita. In XXXI Congresso da Sociedade Brasileira de Computação.

Souza, Anderson A. et al. (2014) Mundo de Euclides: Aplicabilidade de um Jogo para o Ensino da Geometria Euclidiana. In Simpósio Brasileiro de Jogos e Entretenimento Digital (SBGames). 